\title{
El agua como símbolo y componente del espacio en los relatos de Maryse Condé
}

\section{Aceituno Martínez, Eduardo}

Universidad de Granada, eaceitunom@ugr.es

\section{Resumen}

En esta comunicación, me propongo analizar las diferentes funciones que desempeña el agua como componente del espacio narrativo en los relatos cortos de Maryse Condé. Entre ellas, cabe destacar la impresión de realidad generada, así como una función de indicio (en relación con la identidad de los personajes, con sus sentimientos, con la atmósfera), una función estética (vinculada al lenguaje poético), una función simbólica y, por último, la participación del agua en la dinámica de la acción. El estudio de todas estas funciones pone de manifiesto la singular importancia del elemento acuático en la obra de la escritora guadalupeña.

Palabras clave: Maryse Condé; relato corto; espacio narrativo; narratología.

\section{Résumé}

Dans cette communication, je me propose d'analyser les différentes fonctions que l'eau, en tant que composant de l'espace narratif, remplit dans les nouvelles de Maryse Condé. Parmi elles, il faut souligner l'impression de réalité générée, une fonction d'indice (concernant l'identité des personnages, leurs sentiments, l'atmosphère), une fonction esthétique (liée au langage poétique), une fonction symbolique et, pour finir, l'intervention de l'eau dans la dynamique de l'action. L'étude de toutes ces fonctions met en relief l'importance singulière de l'élément aquatique dans l'œuvre de la romancière guadeloupéenne.

Mots-clés: Maryse Condé; nouvelles; espace narratif; narratologie.

\begin{abstract}
In this paper, I intend to analyse the different roles of water as a component of the narrative space in Maryse Condés short stories. Among its functions, I will point out the impression of reality conveyed, along with an indication function (related to the characters' identity and feelings, and to the atmosphere), an aesthetic function (connected to the poetic language), a symbolic function, and finally the participation of water in the plot dynamics. The study of all these functions highlights the remarkable importance of water in the work of the Guadeloupean writer.
\end{abstract}

Keywords: Maryse Condé; short stories; narrative space; narratology. 
Actualmente Maryse Condé no necesita presentación en un coloquio de francesistas. Se trata de una de las más destacadas novelistas del panorama literario actual en lengua francesa. Novelas como Moi, Tituba, sorcière noire de Salem (1986), La vie sans fards (2012) o Traversée de la Mangrove (1989) han obtenido en estos últimos años un relativo éxito comercial y de crítica.

Como en este momento me encuentro preparando mi tesis sobre el escritor Marcel Aymé, me van a permitir que le tome prestada una idea que creo que es importante tener en cuenta para poder apreciar en su justa medida la calidad de la obra de Maryse Condé. En palabras de Marcel Aymé, en una novela «la nature humaine, sensible, [...] importe seule» (Lécureur, 1996: 111). Asimismo, la propia Maryse Condé afirma que toda literatura es «una búsqueda interior, un esfuerzo destinado a dilucidarse a uno mismo» ${ }^{1}$ (Pfaff, 1996: 74). En efecto, Maryse Condé parece compartir la idea de que la novela debe transmitir la impresión de una verdad profunda, debe tratar de acceder a la vida secreta de los seres humanos, a nuestros sentimientos más íntimos y al mismo tiempo universales.

Me he propuesto estudiar el agua como elemento del espacio narrativo en los relatos cortos de Maryse Condé; relatos que fueron recopilados en 1997 en un volumen que lleva por título Pays mêlé. El estudio del espacio en estos relatos me parece bastante pertinente, ya que pone de manifiesto algunos de los rasgos más característicos de la escritura de Maryse Condé. En casi todos los relatos, la autora reserva un papel importante a la naturaleza y, en concreto, la presencia del mar y de los ríos es recurrente. En mi análisis, voy a tratar de determinar la función que cumplen estos elementos en la narración.

La primera constatación es que el mar o el río rara vez poseen un valor meramente referencial; es decir, no tienen como principal función contextualizar la historia en general o una escena en particular. De ahí la necesidad de que el análisis crítico les reserve una atención particular. Hemos de interrogarnos acerca de sus funciones específicas en el seno de la narración.

En su excelente manual Poétique du roman, Vincent Jouve tal vez generaliza demasiado al asimilar el análisis narratológico del espacio y el estudio de la descripción. A fin de cuentas, las referencias al espacio narrativo no siempre están insertas en una secuencia descriptiva, y menos aún cuando nos referimos al género del relato corto, en el que dichas secuencias suelen ralentizar el ritmo y, por ello, son menos frecuentes que en la novela. No obstante, Jean-Michel Adam y André Petitjean enumeran en su obra Le Texte descriptif una serie de funciones de la descripción que considero que se ajustan bastante al estudio que nos ocupa (aunque, como acabo de apuntar, no todas las referencias a ríos o mares en los relatos de Maryse Condé se acompañan de su correspondiente descripción).

Así pues, tomando prestada la terminología de Adam y Petitjean, podríamos hablar en primer lugar de una fonction mimésique del agua como componente del espacio en los relatos de Maryse Condé, la cual consiste en generar una ilusión de realidad, reforzar la verosimilitud de la historia. Ya me he referido previamente a la intención de Maryse Condé de reflejar la realidad humana en su obra, lo que ayuda a entender la importancia de esta función. Una función que, por otra parte, abarca casi todos los elementos del relato, por lo que no nos vamos a detener en este aspecto.

En realidad, las funciones principales del agua como elemento del espacio en estos relatos serían otras dos. La primera de ellas está relacionada con lo que Adam y Petitjean denominan la fonction sémiosique, que consiste en esclarecer el sentido de la historia. Con ello quiero referirme al agua no como símbolo (ciñéndonos a la definición de símbolo como elemento susceptible de una doble interpretación, en el plano realista y en el plano de las ideas), sino más bien como lo que Roland Barthes denomina indicio. Barthes define los indicios como unidades de la narración que se refieren:

non à un acte complémentaire et conséquent, mais à un concept plus ou moins diffus, nécessaire cependant au sens de l'histoire: indices caractériels concernant les personnages, informations relatives à leur identité, notations d' « atmosphères », etc. [...] Pour comprendre « à quoi sert » une notation indicielle, il faut passer à un niveau supérieur (actions des personnages ou narration), car c'est seulement là que se dénoue l’indice (1966: 8-9).

\footnotetext{
${ }^{1}$ La traducción del inglés es mía.
} 
En efecto, las referencias al elemento acuático en los relatos de Maryse Condé no parecen imprescindibles a primera vista para el desarrollo de la trama, pero en realidad encierran una carga de sentido que las convierte en un componente esencial de la narración. Dichas referencias suelen transmitir un significado implícito, casi siempre relacionado con la intimidad de los personajes. La novelista pone así el espacio exterior al servicio de la expresión del mundo interior, lo que, insisto, no significa que recurra a la simbología. Por ejemplo, abundan las escenas en las que un personaje permanece contemplativo frente al agua. El narrador recurre a estas escenas para rebasar los límites de la focalización externa y dar a conocer, o al menos sugerir, los sentimientos del personaje. De esta manera, la escritora proporciona claves fundamentales para comprender el sentido de la historia. Por ejemplo, en el relato No woman, no cry, Maryse Condé nos presenta a una protagonista misteriosa, Létitia, quien despierta el odio y la rabia de los vecinos de su aldea; una animadversión que parece únicamente motivada por la independencia de la mujer, que vive sola. Una escena de contemplación del mar permite que el lector comience a adentrarse al fin en la intimidad de Létitia. Se evoca así su infelicidad, en relación con una íntima ruptura con la sociedad y con una carencia cuya naturaleza se revelará más adelante:

Elle aimait tout particulièrement ce coin qui butait contre le flanc du volcan, inaccessible derrière ses brouillards comme une prêtresse au fond de sa grotte. Si on lui donnait dos, on faisait face au ciel et à la mer, immensités confondues. Aussi on pouvait se persuader qu'à part ces deux éléments rien n'existait, surtout pas l'île porteuse de tellement de malheureux, et que le monde était à naître (1997: 51).

Del mismo modo, el relato Nanna-Ya es la historia del matrimonio formado por Grâce y George, ambos marcados desde la infancia por su condición de hijos bastardos. Este fatídico origen exacerba su sensibilidad y su sensación de soledad y de diferencia frente a un entorno hostil. Una vez más, el agua es el elemento escogido por la novelista para expresar su doloroso aislamiento:

Et Grâce grandit dans la haine de Moore Town. Elle haïssait ce cirque de montagnes qui l'enserrait comme un piège dont elle ne trouverait jamais l'issue. De droite et de gauche, des sommets drapés de brouillard, se confondant avec le gris du ciel. À perte de vue, une végétation dense et hostile, toujours prête à dévorer les précaires jardins de l’homme. Dans le lointain, la rumeur d'un fleuve turbulent qui chaque hivernage réclamait son quota de victimes (1997: 147148).

À présent, George pensait souvent à lui-même comme à un fossile, une laminaire, accrochée à son rocher et lavée inlassablement par la mer (1997: 156).

El desasosiego experimentado por los hijos bastardos es uno de los temas más frecuentes en estos relatos. Se trata de personajes que se ven abocados a padecer conjuntamente la ausencia del padre, la falta de afecto materno y el desprecio de la sociedad, que les niega además cualquier posibilidad de un futuro próspero. Ese desarraigo, esa carencia afectiva, figuran también entre las emociones más intensas que afloran en el relato Pays mêlé. En este fragmento, el paisaje marino y un mar figurado se conjugan y permiten al lector conocer los padecimientos del personaje:

Antoine s’assied à la Pointe Curé et regarde la mer, ce bleu immense sur le corps maltraité de la terre. Il a apporté avec lui un livre qu'il aime : Compère Général Soleil. Mais il ne le lit pas. Il regarde la mer. Il voudrait redevenir un petit enfant. Rentrer dans le ventre de sa mère. Nager dans la mer de son ventre (1997: 128).

Estos fragmentos sirven también de ilustración de la segunda gran función del agua en los relatos de Maryse Condé: una función estética. Como ya se ha podido constatar en este estudio, la escritora guadalupeña muestra un enorme talento para la escritura de textos de un gran lirismo. Al mismo tiempo, se percibe su esfuerzo por dosificar el uso del lenguaje poético, evitando así desdibujar la realidad tras una acumulación de imágenes así como la ralentización del ritmo del relato. Asimismo conviene apreciar el talento del que hace gala Maryse Condé en su búsqueda de un justo equilibrio en la 
expresión poética, de manera que logra mantenerse alejada de los dos extremos en los que resulta tan fácil caer: tanto del idealismo de la exaltación romántica como del prosaísmo superficial.

En concreto, el lenguaje se torna especialmente poético cuando la novelista se propone evocar el esplendor de la naturaleza, y del mar en particular; una celebración de la naturaleza que siempre guarda una estrecha relación con las emociones del personaje, como ya he apuntado. La belleza de las palabras trata de transmitir la belleza del mundo natural, tal y como la percibe el personaje, cuya mirada trasluce además la admiración de la propia escritora frente a la naturaleza de su isla natal. Eso sí, Maryse Condé demuestra una vez más su dominio del estilo motivando ${ }^{2}$ siempre su canto a los elementos, es decir, haciendo que éste contribuya a dar sentido a la historia. De esta manera, consigue estimular la imaginación y la sensibilidad del lector sin caer en absoluto en un exotismo naïf.

En la mayor parte de los casos, las dos grandes funciones del espacio que hemos detectado (la función de indicio y la función estética) aparecen inextricablemente ligadas. La gama de emociones y de figuras de estilo que aparecen asociadas al agua es vastísima.

Personificaciones, metáforas y comparaciones asocian, por ejemplo, mar y sensualidad. No parece haber elemento más apropiado que el agua para evocar la iniciación de la joven protagonista de La châtaigne et le fruit à pain, para quien la capacidad de gozar de la vida y vivir el momento presente aparece ligada a un estado de receptividad sensorial frente a una naturaleza plácida y rica en placeres:

Sans lui, je n'aurais jamais su que les mangues poussent aux manguiers, les quenettes aux quenettiers et les tamarins aux tamariniens des Indes pour la plus grande saveur de nos bouches. Je n'aurais jamais vu que le ciel est tantôt bleu pâle comme l'œil d'un nouveau-né d'Europe, vert sombre comme le dos d'un iguane ou noir comme la noirceur de minuit, et compris que la mer fait l'amour avec lui. Je n'aurais jamais goûté aux pommes-roses de la rivière après le bain (1997: 38).

Del mismo modo, para expresar el intenso deseo de Létitia y el ardor de un encuentro sexual en el relato No woman, no cry, Maryse Condé recurre una vez más al agua, que en esta ocasión conforma un espacio imaginario dentro de la historia, una ficción dentro de la ficción, que se va construyendo exclusivamente por medio de tropos y símiles:

Il la suivait dans son lit à l'heure de la sieste sous les draps trempés d'eau marine. Elle le rejoignait au moment du coucher déjà vautré parmi les taies empesées des oreillers et paré pour ce qui allait suivre. Des fois, il passait tout bonnement la nuit à dormir et elle le serrait contre elle comme son petit enfant. D’autres fois, le jour écarquillait ses deux yeux bleus qu'ils étaient encore à suffoquer et à haleter dans le mitan du lit, pareils à des nageurs en perdition (1997: 53).

Alors, à moitié morts, ils se retrouvèrent sur une plage molle d'où ils respiraient encore l'odeur calcinée de leurs chairs (1997: 57).

Como vemos, la imagen del baño, que supone el contacto más intenso con la naturaleza y el agua, es empleada en repetidas ocasiones por la escritora para evocar el amor y el placer de los sentidos. Sin embargo, las historias de amor de Maryse Condé siempre se tornan dramáticas. Son múltiples los obstáculos, desde la inconstancia masculina hasta las barreras sociales, que hacen que el amor desemboque ineludiblemente en decepción, separación, amargura. También en este caso, la escritora recurre a la imagen del mar para transmitir esa otra cara de la pasión. En Pays mêlé, el personaje de Sandrine tiene que soportar que su amante la engañe con su hermana y trata de poner fin a la situación recurriendo a toda clase de sortilegios, como rodearse de brujos capaces de elevar las olas del mar, o arrojando brebajes mágicos al océano. En el mismo relato, el mar («une mer violette», 1997: 113) es uno de los elementos que contribuyen a crear una atmósfera de horror en los cuadros del pintor Antoine Aubrun, condenado a vivir separado de su amante.

\footnotetext{
${ }^{2}$ Entendiendo la motivación con el sentido que le da Philippe Hamon en su Introduction à l'analyse du descriptif, es decir, como el procedimiento que consiste en justificar la pausa narrativa poniéndola en relación con la lógica de la historia.
} 
Una vez analizadas las dos principales funciones que cumple el agua como componente del espacio, conviene añadir que este elemento juega otro papel importante en numerosos relatos de Maryse Condé, ya que participa directamente en la dinámica de la acción. En Ayissé, por ejemplo, en el momento en que el protagonista se aproxima por el río, a bordo de una barca, a la ciudad donde tiene lugar la acción, dicho personaje describe una atmósfera de ensueño, irreal, y tiene una premonición: «une intuition me soufflait que mon séjour à T. serait peu banal, marqué d’événements qui ne s’effaceraient pas de ma mémoire» (1997: 20). Intuición que se revelará acertada, puesto que el personaje está a punto de experimentar una atracción fatal que le empuja hacia una hermosa mujer y hacia su prometido, una especie de doble, brutal y despiadado, del protagonista.

Este tipo de anticipaciones de la acción, que dan cohesión y sentido a la historia, además de generar suspense, abundan en los relatos estudiados. El relato La Châtaigne et le fruit à pain narra la historia de Étiennise, una niña que paradójicamente detesta a su madre, quien se desvive por ella, y al mismo tiempo idolatra a su padre, irresponsable y vividor. El sufrimiento de la madre al constatar la desafección de su hija se expresa por anticipado a través de la imagen de un mar embravecido, en el momento en que ambas se separan y Étiennise parte a vivir con su padre:

Un matin de fin septembre, ma mère me traça une croix sur le front, m’embrassa sèchement et me confia au capitaine avec mon maigre bagage. Nous eûmes à peine quitté la jetée sur laquelle la foule rapetissait que ma félicité fit place à un sentiment de panique. La mer s'ouvrait comme la gueule d'un monstre, enragé à nous avaler. Nous étions aspirés vers ce gouffre, puis rejetés, vomis avec dégoût avant d'être entraînés à nouveau. Le manège dura deux heures et demie. Des femmes, le rosaire à la main, priaient la Vierge Marie. Enfin nous entrâmes dans une darse violette au fond de laquelle riait Pointe-à-Pitre (1997: 33).

En este caso, es evidente el valor simbólico del mar, elemento escogido por la escritora para expresar el dolor de la madre que ve cómo su hija se distancia de ella inexorablemente, y que contrasta de forma drástica con la ciudad donde vive el padre, un lugar que «ríe» al recibir a Étiennise. Encontramos otro ejemplo de anticipación en Pays mêlé, cuando el joven Antoine se extasía ante la belleza de una isla, cuya descripción culmina así: «Un cimetière aux tombes blanches et noires occupe une baie et semble une fière cité des morts» (1997: 122). Una imagen que se revelará premonitoria del inminente asesinato del personaje en un atentado; muerte que el narrador considera heroica.

Además, el agua puede intervenir directamente en la acción determinando cualquiera de las sucesivas etapas de la historia. Un ejemplo lo ofrece el estado final ${ }^{3}$ o última etapa de la historia de Antoine Aubrun en Pays mêlé: la última aparición del personaje se reduce a una escena en la que se describe su rutinario paseo solitario, que le conduce a un banco desde donde contempla el mar. A través de esta escena, el lector comprende la huella indeleble que ha dejado en el personaje su apasionado amor de juventud, que las circunstancias truncaron. La contemplación del mar transmite así el amargo final de la historia.

Para terminar, voy a referirme a Solo, la narración que tal vez sintetiza mejor todo lo expuesto anteriormente. El relato comienza con una escena que muestra a la protagonista abandonando el pueblo en el que ha trabajado como maestra:

Je n’en finirai jamais de remonter ce fleuve, d'aller à contre-courant. Autour de moi, les eaux étincelantes, apparemment tranquilles, animées en réalité d'une force invisible, sournoise, prête à tout détruire. Sur la rive, les enfants des écoles sont venus regarder le bateau, assister à mon départ furtif, honteux (1997: 9).

Una vez más, encontramos una función simbólica del agua, cuya naturaleza engañosa y letal se corresponde con la cultura de una sociedad que sólo tolera a la maestra provisionalmente, hasta el momento en que considera que ella ha alterado el orden natural de las cosas. La condena automática que ha de acatar la maestra es la exclusión, una exclusión que además la acompaña desde niña por su condición de hija bastarda. La primera escena del relato simboliza, por tanto, la lucha sin fin de esta mujer condenada a la soledad y a la falta de afecto (como subraya el título del relato). No sólo es importante

\footnotetext{
${ }^{3}$ Según la terminología empleada por Paul Larivaille en L’Analyse morphologique du récit.
} 
señalar el valor simbólico del incipit, sino también que éste supone una anticipación y una dramatización de la historia, además de generar suspense por la cantidad de incógnitas que plantea este comienzo in medias res.

El punto culminante de esta historia es la transgresión de la maestra al iniciar una relación secreta con Solo, un vagabundo al que todos tratan de loco y de maldito. El momento en que ambos deciden mostrarse juntos ante los habitantes del poblado supone una tentativa de dejar de «remontar el río» e integrarse en la comunidad, tal y como se expresa de nuevo a través del simbolismo del agua: «Le jour de la fête nous sortîmes dans le grand jour. Nous descendîmes l’Allée du Fleuve, rebaptisée Allée de l’Indépendance et entrâmes au village par la Porte Océane» (1997: 15). Para terminar, las últimas frases del relato retoman la escena inicial de la protagonista forzada a abandonar el pueblo. En este final dramático de la historia, la referencia al río, expresión simbólica de un destino marcado por la marginalidad, es una buena muestra de la función de indicio y la función estética del agua, así como de la implicación de este elemento en la progresión de la historia:

En cette saison, les eaux sont hautes, le fleuve est la seule voie de communication. Qu'y a-t-il au-delà de sa courbe étincelante ? Pour moi, rien sans doute. Mais je porte l'enfant de Solo, le fruit de nos deux exclusions un instant confondues et devenues amour. Pour lui, je dois garder courage. Je veux le réenraciner. Je veux enfouir son cordon ombilical sous un acoma royal. Mère, Terre, qui ne m’avez pas chérie, je vous forcerai à adopter cet enfant (1997: 17).

\section{Referencias bibliográficas}

ADAM, Jean-Michel, Petitjean, André (1990). Le texte descriptif. París: Nathan.

BARTHES, Roland (1966). «Introduction à l’analyse structurale des récits» en Communications, nº 8, p. 1-27.

Conde, Maryse (1997). Pays mêlé : nouvelles. París: Robert Laffont.

HAMON, Philippe (1981). Introduction à l'analyse du descriptif. París: Hachette.

Jouve, Vincent (2003). Poétique du roman. París: Armand Colin.

Larivaille, Paul (1974). «L’analyse morphologique du récit» en Poétique, nº 19, p. 368-388.

LeCureur, Michel (1996). Marcel Aymé. Confidences et propos littéraires. París: Les Belles Lettres.

PFAFF, Françoise (1996). Conversations with Maryse Condé. Lincoln: University of Nebraska Press. 